\title{
LA APROBACION DEFINITIVA DE LA CONSTITUCION Y ESTATUTOS DE MANCOMUNIDADES INTERMUNICIPALES
}

\author{
POR \\ José A. Lopez PELLICER. \\ Profesor titular de Derecho Administrativo.
}

\section{Cuestión planteada}

La posibilidad de llevar a cabo la ejecución de obras y la gestión de servicios públicos municipales cuenta en nuestro ordenamiento jurídico, en el terreno organizativo, con una variedad de fórmulas asociativas de naturaleza diversa. Entre ellas se encuentra, como es bien sabido, la asociación -como tal libre y voluntaria- de municipios que constituye la Mancomunidad intermunicipal, cuyo interés ha suscitado siempre el estudio que de esta figura ha hecho la doctrina (Jordana de Pozas, Albi, Martín Mateo) , y que responde sin duda a la utilidad que ha prestado y presta "hic et nuac" , como lo demuestra el hecho de que cada vez en mayor medida sea utilizada por los municipios para realizar las obras y servicios de su competencia.

Los órganos encargados del gobierno y la gestión municipal son conscientes de que las limitaciones de recursos económicos e incluso de espacio -la falta de adecuación de determinados servicios respecto al territorio de un sólo municipio- sólo puede afrontarse por la vía de la cooperación interadministrativa, que permite la convergencia de intereses y esfuerzos. $Y$ en este sentido la ya clásica fórmula de la intermunicipalidad a que nos referíamos permite resolver no pocas dificultades que, eventualmente, la actuación municipal aislada quizá no podría solventar, al menos de forma adecuada. Sin ir más lejos, piénsese por ejemplo en la exigencia-deber-que a los municipios impone la Ley $7 / 1985$, en su artículo 26 , de prestar determinados servicios, de los cuáles algunos, como el de recogida de residuos, abastecimiento de agua potable y alcantarillado, han de realizarse en principio -si no recae la oportuna "dispensa" autonómica de la obligación en todo municipio, por tratarse de servicios vitales y a los que por ello tienen derecho todos los ciudadanos (art. 18, 1, g) por afectar a un minimum de calidad de la vida.

Es indudable que respecto de estos servicios públicos, y otros que reciben el mismo tratamiento en el propio precepto legal, la conve- 
niencia de efectuar su prestación de forma asociada, con otros municipios mediante la constitución de un mancomunidad entre ellos 10 bien con otros entes públicos supralocales, por la vía del consorcio) es la que podrá hacer viable y dar efectividad a esta exigencia, que de otro modo podría quedar desentendida y que por ello habría que aplicar, con asistencia de la cooperación provincial (arts. 26, 3, y 92, 3, Ley cit.), evitando y limitando en consecuencia la posible dispensa autonómica a los estrictos términos a que la propia Ley básica condiciona su aplicación.

Siendo, pues, evidente el interés que la figura de la mancomunidad intermunicipal como instrumento jurídico a estos efectos tiene, parece oportuno detenerse una vez más en su estudio, aunque este estudio sólo se limite ahora a examinar, a la luz de la jurisprudencia, la cuestión referente a la naturaleza de los acuerdos aprobatorios de su constitución y estatutos por los municipios que, libre y voluntariamente, deciden asociarse para realizar en común determinadas obras y servicios de su competencia.

La cuestión no carece ni mucho menos de trascendencia si se advierte que, por lo pronto, en el tema se halla implícito el ejercicio de la autonomía local, que la Constitución vigente reconoce y garantiza (arts. 137 y 140) , y que esto condiciona la significación y alcance del control que a la Comunidad Autónoma corresponda en su caso respecto a dichos acuerdos, como vamos a ver.

\section{Naturaleza de acuerdo aprobatorio de la Mancomunidad por los municipios que se asocian}

La Ley $7 / 1985$ establece, en su artículo 44, 3, con carácter básico, el cauce procedimental que ha de seguirse para elaborar y aprobar los Estatutos y constituir la Mancomunidad. Al margen de otras cuestiones que suscita el precepto (1) , y presuponiendo ahora que el proyecto de Estatutos elaborado ha sido objeto de información pública y audiencia mediante informe de la Diputación o Diputaciones provinciales interesadas, interesa centrar nuestra atención en el carácter del acuerdo que corresponde adoptar a continuación a cada uno de los municipios que pretendan asociarse. El artículo $44,3 \mathrm{c}$ ) de la Ley bási-

(1) Así especialmente la forma de articular orgánicamente la asamblea "ad hoc", de los concejales de todos los municipios promotores de la Mancomunidad, para elaborar los Estatutos (exigencia poco operativa, y que no es óbice, para que lo sea, a que se constituya una Comisión que elabore éstos antes de someterlos a la asamblea, y a que ésta se constituya con mayoria absoluta y funcione con mayoria relativa). 
ca -que no de bases, a pesar de su titulo- se limita a decir a este respecto que "los Plenos de todos los Ayuntamientos aprueban los Estatutos".

Ahora bien, como sin perjuicio de esta normativa básica del iter procedimental que ha de seguirse en la órbita local, la legislación de régimen local o autonómica puede establecer algún tipo de intervención de la correspondiente Comunidad Autónoma (2), si en este caso se hubiese establecido la aprobación posterior por la Administración autonómica, en ejercicio de poderes de tutela administrativa, ¿qué acto tiene carácter definitivo, al acto municipal o el acto de aprobación por aquélla?. La respuesta que a esta cuestión da nuestro más alto Tribunal de Justicia considera que la aprobación por una Administración distinta -de la municipal- ha de calificarse como una manifestación de la potestad de fiscalización, como requisito o presupuesto de eficacia, pero no de la validez de la aprobación municipal, que es la que tiene carácter definitivo.

A partir de la consideración del municipio como entidad dotada de autonomía que no puede ser menoscabada por controles de "tutela" que pudieran afectar al ejercicio de la competencia material de aquél , se afirma que han quedado sin efecto las funciones que la legislación anterior atribuída a la Administración del Estado en relación a las Corporaciones locales y, por lo mismo, asumidas por las Comunidades Autónomas como consecuencia del proceso de transferencias realizadas a su favor, y que por ello la decisión o acto resolutorio que, en definitiva, constituye la Mancomunidad corresponde a los municipios que se asocian a ella.

La sentencia del Tribunal Supremo de 8 de junio de 1990 (Sala Especial, en revisión), rescinde otra anterior de la Sala $3^{3}$ del propio Tribunal de 3 de julio de 1989, y tras traer a colación la evolución legislativa respecto a la constitución de mancomunidades municipales (3), considera que:

(2) Con base en su respectivo Estatuto de Autonomía y las oportunas transferencias

(3) Se refiere, en su F.J. 2 a que la aprobación correspondía en un principio al Consejo de Ministros, que podía denegarla no sólo por motivos de legalidad sino también de oportunidad, potestad cuya cobertura era un concepto jurídico indeterminado (el interés público) , con un margen muy amplio de discrecionalidad (art. 13,2, del R.D. $3046 / 1977$, de 6 de octubre) y que en el período de la transición política, dentro del balbuciente sistema preautonómico, fue transferida a la Junta de Galicia (R.D. 1014/1979, de 13 de febrero). Asi las cosas, se promulgan a finales de ese año la Constitución y dos después la Ley Orgánica 1/1981, de 6 de abril, donde se ratifica el traspaso de tal competencia fiscalizadora (art. 27,2, del Estatuto de Autonomia), si bien reducida al 
"no parece dudoso que la asociación voluntaria de municipios se produce y consuma cuando se ha conseguido el consentimiento de todos, expresado por el órgano "ad hoc" de cada uno de ellos, en estos casos el Pleno. El acto plural en que consiste ese acuerdo de voluntades es el final de procedimiento. En cambio, la aprobación posterior, por una Administración distinta, con base territorial más extensa, ha de calificarse como una manifestación de la potestad de fiscalización y, en definitiva, como uno de los requisitos o presupuestos de la eficacia a los cuáles alude el art. 45 de la Ley de Procedimiento Administrativo. Aquí es donde la sentencia impugnada se confunde por calificar este acto de control como "resolutorio", sin serlo.

Por otra parte -añade-, esta su naturaleza intrínseca significa que la exigencia de aprobación interfiere y menoscaba la autonomía municipal consagrada por la Constitución (137 y 140). Ese control, como otros también desaparecidos, responde a la vieja idea de la minoría de edad de los entes municipales, necesitados de una "tutela" , así denominada y como tal configurada en las sucesivas Leyes del ramo, concepción que arranca desde los albores de nuestro régimen local en el siglo XIX pero llega hasta nuestros dias. La Constitución ha venido a emanciparlos y liberar a ese "estado llano" o tercera "esfera" de las Administraciones públicas para infundirles la plenitud de vida y personalidad. En tal sentido se han pronunciado no sólo las sentencias de esta Sala Especial mencionadas más arriba, sino otras tres, al menos, de la misma Sala Cuarta (1 de junio de 1988, 23 de octubre de 1989 y 21 de abril de 1990).

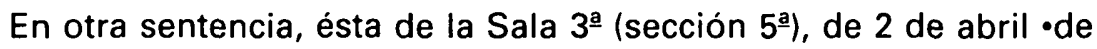
1990 (art. 3410), recaída en un recurso de apelación promovido por la Generalidad de Cataluña, se confirma la dictada por la Sala de lo Contencioso-Administrativo de la Audiencia Territorial de Barcelona, y se había mantenido la tesis también mantenida después por la Sala Especial del Tribunal Supremo (en la citada Sentencia de 8 de Junio de 1990). A la luz del articulo 45 de la Ley $7 / 1895$, considera que :

control de legalidad, con exclusión del de oportunidad por menoscabar éste el principio de autonomía municipal según el Tribunal Constitucional (S. 2 de febrero 1981). Finalmente, la Ley de Bases del Régimen Local 7/1985 de 2 de abril, atribuye la constitución de las Mancomunidades a "los Plenos de todos los Ayuntamientos" participantes, eliminando asi la interferencia de las Comunidades Autónomas (y de la Administración General), que no obstante está habilitada para dictar normas de procedimiento al respecto (art. $44.3, \mathrm{c}$ ). 
"literalmente son cosas distintas el acto administrativo por el que se resuelve el expediente poniendo fin al procedimiento, propiamente dicho, y que la eficacia o ejecutividad del mismo se demore hasta que se produzca la aprobación "superior" a que se refiere, -ya que el acto de aprobación es independiente del previo resolutorio que es objeto de la misma- $y$, aunque se admitiera una hermenéutica contraria, prolongar en casos como el presente para la Administración autonómica una competencia en beneficio de quien ya no ostenta rango jerárquico alguno de superioridad sobre los entes creadores del acuerdo objeto de aprobación -por cierto, cuando legalmente se le ha privado de aquella-, conculcaría lo dispuesto por la legislación del Estado en el apartado c) del artículo 44,3, citado -que traslada esa competencia a los Plenos de los Ayuntamientos que se mancomunan- $y$, en relación con ello, el artículo $47,3, \mathrm{~b}$, de la misma Ley, y lo que, derivativamente, dispone el 35.3 del Decreto-legislativo de 18 de abril de 1986, según el cual los acuerdos aprobatorios de la constitución y Estatutos de la mancomunidad deberán adoptarse por cada Ayuntamiento con el voto favorable de la mayoria absoluta del número legal de miembros de la Corporación, previa información pública por plazo de un mes", infringiéndose, por otra parte, lo que dispone el Reglamente de Población y Demarcación territorial y la propia Ley catalana antes citada, $y$, lo que podría ser más grave, el principio de autonomía municipal consagrado por los artículos 137 y 140 de la Constitución, fuera de cuyo marco no pueden ejercerse facultades claramente contrarias a su letra y a su teleología, y de ahi que sea procedente confirmar la sentencia recurrida.

En análogo sentido, se había expresado la sentencia de 1 de junio de 1988 (Art. 4465) y la de 23 de octubre de 1989 (Art. 7475), cuya tesis ha venido a consolidarse por tanto, según las consideraciones que quedan expuestas.

En suma, pues, cabe concluir diciendo que, en cuanto legislación básica, el precepto contenido en el articulo 44 de la Ley 7/1985 vincula a las Comunidades Autónomas, cuya actuación a este respecto ha de reconocer en todo caso el derecho de los municipios implicito en su autonomía- a asociarse libre y voluntariamente, para realizar en común determinadas obras y servicios comprendidos en el ámbito de su competencia, a cuyo efecto y a través del procedimiento regulado con tal carácter -básico-, el acto administrativo que pone fin al mismo de modo resolutorio y definitivo es el adoptado por el órgano plenario, el ayuntamiento pleno, de cada uno los municipios (eso sí , con el quorum del artículo 47,3 , b) que se asocian. El acto plural en 
que consiste este acuerdo de voluntades, como dice la sentencia de 8 de junio de 1990, es el final del procedimiento. $Y$ en consecuencia, la intervención o aprobación que, en su caso, se atribuya a la Comunidad Autónoma según su legislación, no podrá desvirtuar esta competencia municipal básica $y$, a lo sumo, podrá legalmente condicionar su eficacia, pero nunca su validez y existencia. 